\title{
New lab-made coagulant based on Schinopsis balansae tannin extract: synthesis optimization and preliminary tests on refractory water pollutants
}

\author{
J. Sánchez-Martín • J. Beltrán-Heredia • \\ B. Coco-Rivero
}

Received: 31 January 2013/Accepted: 7 November 2013/Published online: 27 November 2013

(c) The Author(s) 2013. This article is published with open access at Springerlink.com

\begin{abstract}
Quebracho colorado tannin extract was used as a coagulant raw material for water and wastewater treatment. The chemical synthesis follows a Mannich reaction mechanism and provides a fully working coagulant that can remove several pollutants from water. This paper addresses the optimization of such synthesis and confirms the feasibility of the coagulant by testing it in a preliminary screening for the elimination of dyes and detergents. The optimum combination of reagents was $6.81 \mathrm{~g}$ of diethanolamine (DEA) and $2.78 \mathrm{~g}$ of formaldehyde (F) per $\mathrm{g}$ of tannin extract. So obtained coagulant was succesfully tested on the removal of 9 dyes and 8 detergents.
\end{abstract}

Keywords Water coagulation - Quebracho colorado · Tannins $\cdot$ Natural treatment $\cdot$ Design of experiments

\section{Introduction}

Environmental concerns are growing important rapidly nowadays because the fragile Earth equilibrium is being broken due to antropic actions. It is more than evident that the current rate of waste production, exhausting resources, and contamination is not sustainable any more since we are

\footnotetext{
J. Sánchez-Martín ( $\square$ )

Department of Science and Mathematics Education, Faculty of Education, University of Extremadura, 06071 Badajoz, Spain e-mail: jsanmar@unex.es

J. Beltrán-Heredia $\cdot$ B. Coco-Rivero

Department of Chemical Engineering and Physical Chemistry, Faculty of Science, University of Extremadura, Badajoz, Spain e-mail: jbelther@unex.es

B. Coco-Rivero

e-mail: bcocor@gmail.com
}

living in a finite planet (Dorf 2001) where mankind must tend to live in a cycle model rather than a linear vision of the environment (Schumacher 1987). This is the philosophy of the well-known 3R: recycle, reuse, and reduce. Modern life is not possible if we live like Earth had no limits, and the presence of such limits is the basis of conservation and ecologism.

Scientific community is also worried about environmental sustainability, and every day, more and more scientists develop cleaner technologies for guaranteeing the legacy we will leave to our children. Many of these initiatives are focused in water management and water and wastewater treatment even for Developing Countries, in a technologically scarce scenario (Chinyama et al. 2012).

Water is known as a universal vector for the planetary chemistry. Almost everything can be dissolved in water and aqueous effluents are the natural ways of disseminating nutrients and poisons (Buzier et al. 2011). Through aquatic paths pollutants can reach living organisms, either the simpliest ones and the most complex animals, even humans (Ying 2006; Halling-Sorensen et al. 1998; Shaul et al. 1991). Taking care of the environment, as well as taking care of the mankind, means caring the water (WHO 2008).

For this task, there are lots of remediation methods focused on polluted water or on drinking water for making it safe for human consumption. One of the main methods used is coagulation. It is a physical process, so it does not involve chemical reactions (Andriamirado 2007) that is intended to destabilize the suspended colloidal matter in the water matrix. This destabilization is due to the electrical charges compensation, so positive-charged pollutants (cationic ones) usually respond to anionic coagulants whereas negative-charged ones do the contrary (Bulatovic 2007). Coagulants are called, therefore, to be anionic, cationic or, in the most favorable cases, amphoteric.

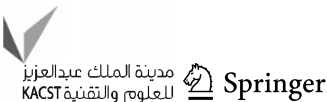


Classical coagulants involved in water treatment are metalic salts such as $\mathrm{Al}_{2}\left(\mathrm{SO}_{4}\right)_{3}$ or $\mathrm{FeCl}_{3}$. They were widely used above all in drinking water treatment. However, some significant concerns have recently arosen, linking, for example, the use of alum to Alzheimer's disease (Flaten 2001). This and other environmental problems have pushed scientists to research on new coagulants, mainly based on natural products, to overcome such disadvantages (Sharma and Sanghi 2012).

In this particular vision of sustainability, coagulants can be synthesized from many different raw substances. One of the most promising natural materials are tannins and specifically tannin extracts from Schinopsis balansae, that is, Quebracho colorado. This vegetal species was the main feedstock of tannin extract for a long time, until Acacia mearnsii, black wattle, was industrially used. Tannin extracts are natural astringent products that are widely used for leather tanning (hence their name), but of late many other uses are being found (Pizzi 2008). Their use as coagulant precursors is one of the most interesting capacities tannin extracts seem to present (Beltrán-Heredia et al. 2010)

When talking of natural tannin extracts we are focusing our attention on vegetal water-soluble polyphenolic compounds with an exact chemical composition difficult to determine due to the large amount of impurities they usually contin. Economical reasons encourage scientists to work directly with this raw materials, without purifications. This is usually feasible, as we have reported previously (Beltrán-Heredia et al. 2011a, b, c, d, e, f). Namely, the nature of Quebracho tannins have been thoroughly characterized by specific researchers (Vivas et al. 2004) and it is said that is mainly based on combinations of catechol, resorcinol, and pyrogallol building blocks that provide a large structure where different operating changes can be performed. The feasibility of this raw material for coagulant synthesis is fully demonstrated since it is used as feedstock for commercially available coagulants, such as Silvafloc (Beltrán-Heredia et al. 2009a).

Tannins have been used as a source of novel coagulants because they presented interesting characteristics that make them useful according to sustainability principles (Starkl and Brunner 2004; Muga and Mihelcic 2008). They are affordable and ubiquitous compounds since they can be obtained from a wide variety of barks (Haslam 1989). Alternatively, they are easy to extract and handle (Matthews et al. 1997) and their use does not affect environmental equilibrium because they can be employed in little amounts (Nakamoto et al. 2004). These and other sustainability premisses make tannins optimum candidates for the production of new water treatment agents.

The polymerization of the tannin extract is known to follow a Mannich reaction pattern. This chemical process is well known and we have previously explained it (BeltránHeredia et al. 2011a, b, c, d, e, f). Figure 1 shows the mechanism of this reaction, which is namely split off in two steps: (1) the initial formation of the imine and (2) the formation of the Mannich base. As a result of this chemical transformation, an electrically charged coagulant (cationic) is produced and, therefore, can be used in the destabilization of anionic compounds, suspended in water matrices.

Although there are, as we said before, examples of commercial coagulants made with this tannin extract, there are no references of the optimization of the synthesis of such product. Many variables are involved in the production process: from the relative amounts of reagents up to operating variables such as $\mathrm{pH}$, temperature, etc. To the best of our knowledge, this researching field is completely empty, with the exception of our own previous paper (Beltrán-Heredia et al. 2010). This work aims to optimize the operating process of coagulant synthesis from Schinopsis balansae with diethanolamine and formaldehyde according to a specific design of experiments, analyzed following the response surface methodology. An optimum coagulant is obtained and its utility is experimentally confirmed with the removal of detergents and dyes in aqueous effluents.

This paper proceeds in the following way: first we performed a qualitative searching for the most suitable operating range regarding the different working parameters involved in the optimization process (mainly reagents dosages, but also $\mathrm{pH}$ level and reaction time). Then, a Design of Experiments was attempted to isolate the best combination of these working parameters. To identify this category, a standard jar-test on a particular dye (Alizarin Violet 3R) was carried out and then the conclusions on this pollutant were extended to the rest of them. Finally, the optimum coagulant product was tested on up to 9 dyes and 8 surfactants. This is the working protocol we followed in previous papers (Beltrán-Heredia et al. 2009b, 2011a, b, c, d, e, f).

\section{Materials and methods}

Experimental installations

\section{Coagulant synthesis reactor}

For the synthesis of every coagulant, following the specific procedure for each combination (according to the experimental plan in section "Design of experiments"), the experimental reactor consisted of the following:

- A thermostatic bath equipped with thermocontrol (SELECTA, Tectron Bio, Spain) which adjusted 
Fig. 1 Reaction mechanism of aminomethylation for coagulant synthesis. 1 Formation of imine. 2 Formation of Mannich base

Fig. 2 Synthesis reactor experimental installations

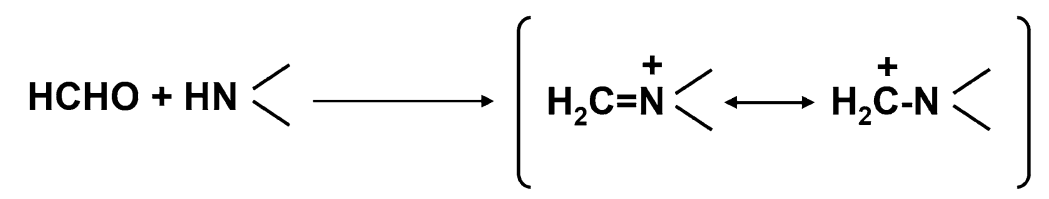

[1]

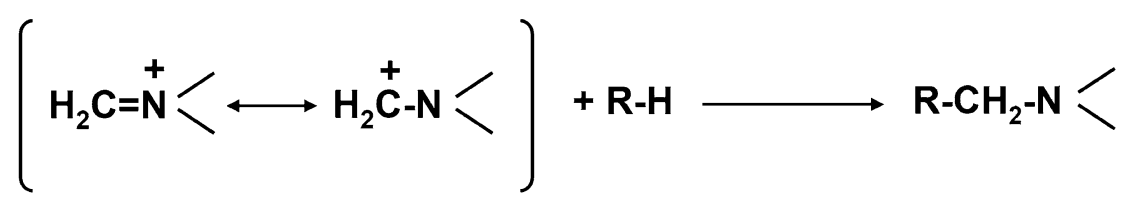

[2]

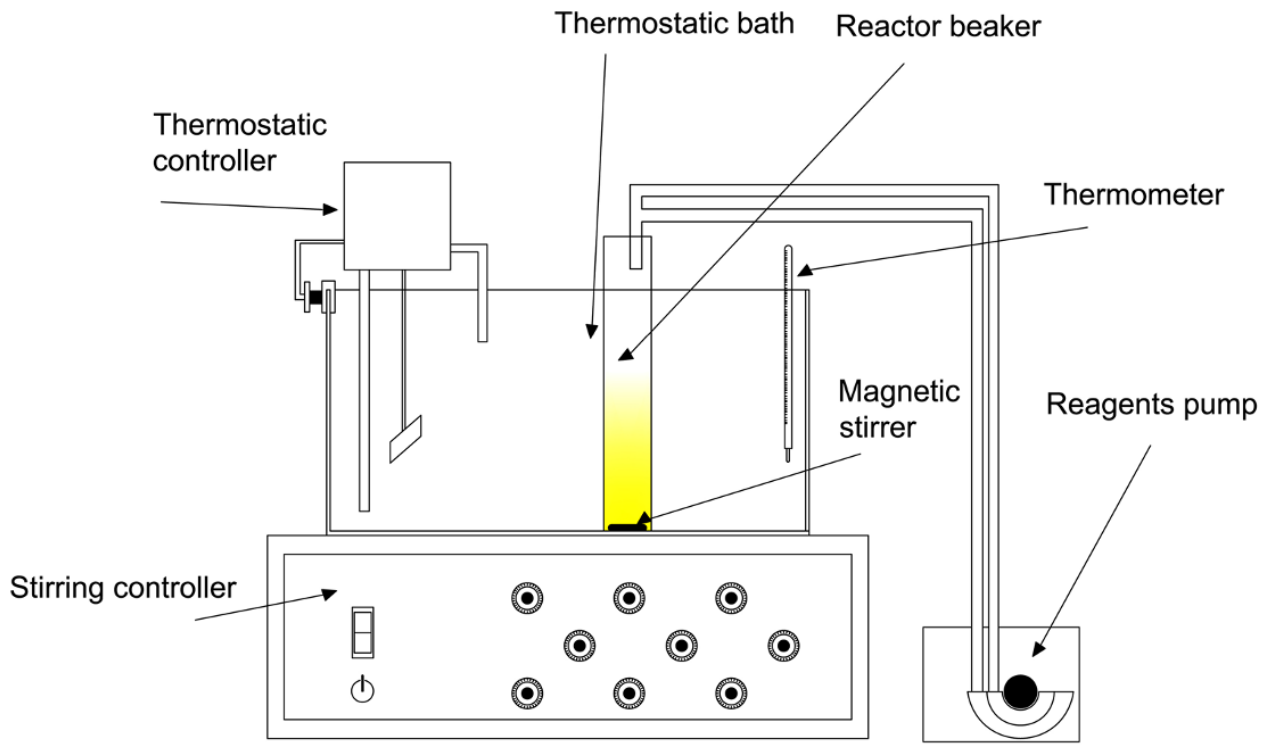

temperature within a range of $\pm 0.5^{\circ} \mathrm{C}$. A manual termomether confirmed this point.

- A multi-stirrer magnetic device (SELECTA, Multimatic 9N, Spain) that kept the reaction mixture homogeneous with the aid of a teflon-covered magnetic bar.

- A double-channel peristaltic hydraulic pump calibrated for the specific reagents (Cole Parmer, MasterFlex $\mathrm{C} / \mathrm{L}$ ).

- Glass beaker reactor (diameter $3.5 \mathrm{~cm}$, height $18 \mathrm{~cm}$ ).

The whole system is presented in figure 2 .

\section{Coagulation Jar test}

For evaluating the coagulation performace of the synthesized products, they were tested according to a standard protocol which was previously used in other works (Beltrán-Heredia et al. 2011a, b, c, d, e, f). $100 \mathrm{~mL}$ of a sample of a known concentration of each contaminant was introduced in a $0.5-\mathrm{L}$ beaker. Subsequently, $1.5 \mathrm{~mL}$ of the corresponding coagulant was added and the Jar Test apparatus (JLT4, Velp Scientifica) was programmed to 100 rpm for $2 \mathrm{~min}, 30 \mathrm{rpm}$ for $60 \mathrm{~min}$. The coagulation process is over after these periods as we reported in previous papers (Beltrán-Heredia et al. 2010).

\section{Buffered solutions}

The trials with added pollutant were performed with $\mathrm{pH}$ stable media. To this end, a $\mathrm{pH}-7$ buffer solution was prepared of $1.2 \mathrm{~g}$ of $\mathrm{NaH}_{2} \mathrm{PO}_{4}$ and $0.88 \mathrm{~g}$ of $\mathrm{Na}_{2} \mathrm{HPO}_{4}$ in 1 $\mathrm{L}$ of distilled water. The $\mathrm{pH}$ was then adjusted to 7 with $\mathrm{HCl} 1 \mathrm{M}$ or $\mathrm{NaOH} 1 \mathrm{M}$. All reagents were of analytical grade from PANREAC.

\section{Reagents and model compounds}

The synthesis of the tannin-based coagulants involved the following reagents:

- Tannin extract from Schinopsis balansae (Raoul-Duvall, France).

- Formaldehyde $37 \%$, stabilized with methanol (Merck).

- Diethanolamine solution, analytical purity grade (Aldrich). 
<smiles>[NH3+]OC(=O)c1nn(-c2ccc(S(=O)(=O)O[Na])cc2)c(O)c1N=Nc1ccc(S(=O)(=O)O[Na])cc1</smiles><smiles>[Y]OS(=O)(=O)C1=Cc2cc(S(=O)(=O)O[Na])ccc2C(=NNc2ccc(S(=O)(=O)O[Na])c3ccccc23)C1=O</smiles><smiles>O=C1C(=C2C=Cc3ccccc3N2)C(=O)c2ccccc21</smiles>

6<smiles>Nc1c(S(=O)(=O)O[Na])cc(Nc2cccc(S(=O)(=O)CCOS(=O)(=O)O[Na])c2)c2c1C(=O)c1ccccc1C2=O</smiles><smiles>Cc1ccc(N)c(S(=O)(=O)[O-])c1</smiles><smiles>Cc1cccc2c1C(=O)c1cccc(N)c1C2=O</smiles><smiles>Cc1cccc(S(=O)(=O)[O-])c1</smiles>

8<smiles>COc1cc(-c2ccc(N=Nc3ccc4c(S(=O)(=O)[O-])cc(S(=O)(=O)O[NH3+])c(N)c4c3O)c(OC)c2)ccc1N=Nc1ccc2c(S(=O)(=O)[O-])cc(S(=O)(=O)[O-])c(N)c2c1O</smiles><smiles>N#Cc1cc([N+](=O)[O-])cc2c(N=Nc3c(O)ccc4ccccc34)c(O)cc(S(=O)(=O)[O-])c12</smiles>

Fig. 3 Chemical structures for dyes. 1 Tartrazine, 2 Carmine indigo, 3 Amaranth, 4 Patent blue V, 5 Quinoline yellow WS, 6 Remazol brilliant blue, 7 Alizarin violet $3 \mathrm{R}, 8$ Chicago sky blue $6 \mathrm{~B}, 9$ Palatine fast black WAN

\section{Model compounds}

According to previous works (Sánchez-Martín et al. 2010a; Beltrán-Heredia et al. 2011a, b, c, d, e, f) we have checked the feasibility of the synthesized coagulants with a model dye. This is Alizarin Violet $3 \mathrm{R}\left(\mathrm{C}_{28} \mathrm{H}_{20} \mathrm{~N}_{2} \mathrm{Na}_{2} \mathrm{O}_{8} \mathrm{~S}_{2}\right)$, an anthraquinonic dye with molecular weight equal to $622.6 \mathrm{~g} \cdot \mathrm{mol}^{-1}$. It was supplied by Sigma-Aldrich (USA).

Up to nine diffent dyes, including Alizarin Violet 3R, were considered in the current paper. They are Carmine Indigo
$\left(\mathrm{C}_{16} \mathrm{H}_{8} \mathrm{~N}_{2} \mathrm{Na}_{2} \mathrm{O}_{8} \mathrm{~S}_{4}\right)$, Chicago sky blue $6 \mathrm{~B} \quad\left(\mathrm{C}_{34} \mathrm{H}_{24} \mathrm{~N}_{6}\right.$ $\left.\mathrm{Na}_{4} \mathrm{O}_{16} \mathrm{~S}_{4}\right)$, Palatine fast black WAN $\left(\mathrm{C}_{60} \mathrm{H}_{36} \mathrm{~N}_{9} \mathrm{O}_{21} \mathrm{Na}_{3} \mathrm{~S}_{3} \mathrm{Cr}_{2}\right)$, Amaranth $\left(\mathrm{C}_{20} \mathrm{H}_{11} \mathrm{~N}_{2} \mathrm{Na}_{3} \mathrm{O}_{10}\right)$, Patent blue $\mathrm{V}\left(\mathrm{C}_{27} \mathrm{H}_{31}\right.$ $\left.\mathrm{N}_{2} \mathrm{~S}_{2} \mathrm{O}_{7} \mathrm{Na}\right)$, Quinoline yellow $\left(\mathrm{C}_{18} \mathrm{H}_{13} \mathrm{NO}_{5} \mathrm{SNa}\right)$, Remazol Brilliant Blue $\left(\mathrm{C}_{22} \mathrm{H}_{16} \mathrm{~N}_{2} \mathrm{Na}_{2} \mathrm{O}_{11} \mathrm{~S}_{3}\right)$ and Tartrazine $\left(\mathrm{C}_{16} \mathrm{H}_{9} \mathrm{~N}_{4}\right.$ $\mathrm{Na}_{3} \mathrm{O}_{9} \mathrm{~S}_{2}$ ). Their chemical structures are shown in Fig. 3. All of them were supplied by Acros (USA).

Detergents are long-chain anionic surfactants and this chemical family includes a large variety of products. Some of them are polyoxyethylene (3.5) sodium lauryl ether sulfate 
<smiles>CCCCCCCCCCCCc1ccc(S(=O)(=O)O[Na])cc1</smiles>

1

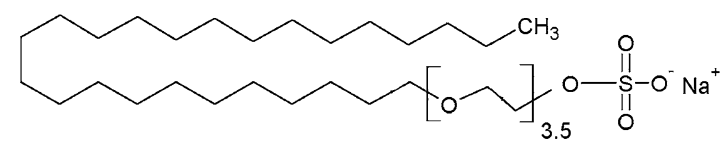

3<smiles>CCCCC(CC)COC(=O)CC(C(=O)OCC(CC)(CC)CCCC)S(=O)(=O)[OH2+]</smiles>

5

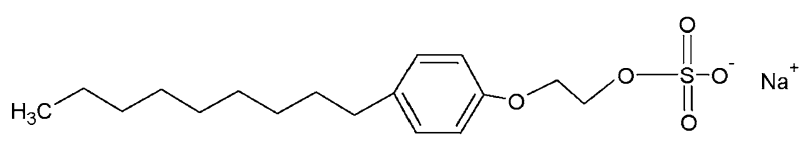

7

Fig. 4 Chemical structures for surfactants. 1 Sodium dodecylbenzene sulfonate (SDBS). 2 Sodium dodecyl diphenyl ether disulfonate (SDDED). 3 POE (3.5) sodium lauryl ether sulfate (SLES). 4 Sodium

(SLES, $\mathrm{C}_{12} \mathrm{H}_{25}\left(\mathrm{OCH}_{2} \mathrm{CH}_{2}\right)_{3.5} \mathrm{OSO}_{3} \mathrm{Na}$ ), sodium dodecylbenzene sulfonate (SDBS, $\mathrm{C}_{18} \mathrm{H}_{29} \mathrm{SO}_{3} \mathrm{Na}$ ), sodium laurylsulfate ( $\mathrm{SLS}, \mathrm{CH}_{3}\left(\mathrm{CH}_{2}\right)_{11} \mathrm{OSO}_{3} \mathrm{Na}$ ), sodium dodecyl diphenyl ether disulfonate (SDDED, $\mathrm{C}_{35} \mathrm{H}_{56} \mathrm{~S}_{2} \mathrm{O}_{7} \mathrm{Na}_{2}$ ), sodium dioctyl sulfosuccinate (SDSS, $\mathrm{C}_{20} \mathrm{H}_{37} \mathrm{SO}_{7} \mathrm{Na}$ ), Polyoxyethylene sodium nonylphenol sulfate (SNS, $\mathrm{C}_{17} \mathrm{H}_{28} \mathrm{SO}_{5} \mathrm{Na}$ ), sodium triethanolamine lauryl sulfate (TEALS, $\mathrm{C}_{18} \mathrm{H}_{40} \mathrm{NSO}_{4} \mathrm{Na}$ ) and sodium lauryl sulfoacetate (SLSA, $\mathrm{C}_{14} \mathrm{H}_{27} \mathrm{SO}_{5} \mathrm{Na}$ ). All of them were purchased from CHEM SERVICE Inc. (USA). Chemical structures of these surfactants are shown in Fig. 4. These were selected as model compounds for testing the removal ability of this new coagulant, although further studies could include other varieties.

Synthesis of the coagulants

$2.5 \mathrm{~g}$ of the tannin extract was introduced in the reactor beacker. Subsequently, they were dissolved with a given volume of

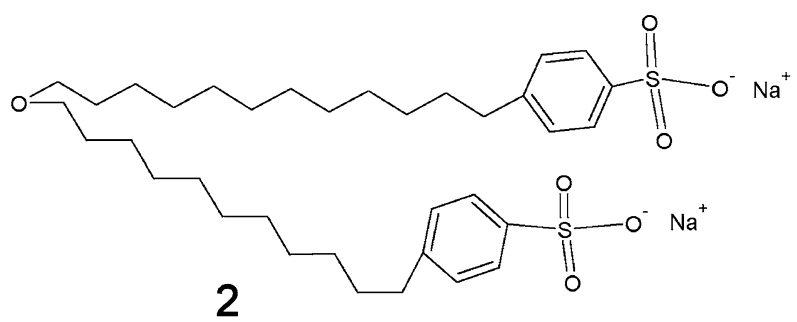<smiles>CCCCCCCCCCCCOC(=O)CS(=O)(=O)O[Na]</smiles>

4<smiles>CCCCCCCCCCCCOS(=O)(=O)O[NH+](CO)CO</smiles>

6<smiles>CCCCCCCCCCOS(=O)(=O)[O-]</smiles>

8

lauryl sulfoacetate (SLSA). 5 Sodium dioctyl sulfosuccinate (SDSS). 6 Sodium triethanolamine lauryl sulfate (TEA-LS). 7 POE sodium nonylphenol sulfate (SNS). 8 Sodium lauryl sulfate (SLS)

diethanolamine (DEA) and $10 \mathrm{~mL}$ of distilled water. This solution is thermostated at a constant temperature of $30{ }^{\circ} \mathrm{C}$. The polymerization of the coagulant is achieved by adding a given volume of fomaldehyde drop by drop. The entire process usually takes $1 \mathrm{~h}$ and the reaction is left in the same conditions of stirring and temperature for $24 \mathrm{~h}$ for ageing.

Previous works (Sánchez-Martín et al. 2010b) evidenced the idoneity of such kind of coagulants in the removal of organic compounds from water and wastewater treatment. One of the main advantages we presented in that paper was the fact that no extra tannin content is kept in water after the removal process, so there is no need for further cleaning procedures.

Analytical determination of pollutants in water matrix

Dye concentration was determined by direct visible spectroscopy in a HEXIOS UV/VIS spectrophotometer. 
According to Lambert-Beer's law, a direct relationship is established between the absorbance of the sample and the pollutant concentration. Different wavelenghts were used for each colorant.

Surfactant removal was determined by visible spectrophotometry according to a method based on its association with methylene blue (Tôei and Fujii 1977).

Mathematical and statistical procedures

A factorial central composite (CCD) orthogonal and rotatable design was used for the optimization of the quantitative variables involved in the adsorbent synthesis. The CCD analysis was carried out under response surface methodology. Design of experiments section was statistically analyzed using StatGraphics Plus for Windows 5.1 (StatPoint Technologies Inc., 2009).

\section{Results and Discussion}

The coagulation process with these kinds of materials is called adsorption-like coagulation (Beltrán-Heredia et al. 2011a, b, c, d, e, f). We have worked on the hypothesis that pollutant removal by coagulation and flocculation process may involve two stages. At first destabilization of colloids, that may be ruled by chemical interactions between coagulant molecules (cationic, positive charged) and pollutant molecules (anionic, negative charged). Then, when the complex coagulant-pollutant is formed, flocs begin to grow by sorption mechanisms. This should be the controlling stage, so the whole process can be simulated as an adsorption phenomenon (Nazaroff and Álvarez-Cohen 2001; Miller et al. 2008).

\section{Design of experiments}

It is not possible to predict the combined influence of the different variables on the final response unless specific experimentation is carried out. Although some theoretical approaches can be done, the empirical evidence of the real influence of the operative conditions can be established only through the experimentation. Design of experiments is a statistical procedure focused on detecting these links between the working variables and can reduce significantly the number of experiments, keeping, however, the reliability of the conclusions at a high standard.

Traditionally, researchers have used the experimental method called one factor at a time. Through this approach, it is very difficult to establish the corresponding relationships amongst all the input factors and the output responses. Instead, it is usually accepted this method can be useful in finding predominant variables, but afterwards a design of
Table 1 Working parameters in the design of experiments

\begin{tabular}{llllll}
\hline $\begin{array}{l}\text { Experimental } \\
\text { run }\end{array}$ & $\begin{array}{l}\text { Coded } \\
\text { dose } \\
\text { DEA }^{a}\end{array}$ & $\begin{array}{l}\text { Coded } \\
\text { dose }\end{array}$ & $\begin{array}{l}\text { Real } \\
\text { amount } \\
\text { DEA }^{a}(\mathrm{~mL})\end{array}$ & $\begin{array}{l}\text { Real } \\
\text { amount }\end{array}$ & $\begin{array}{l}\text { Average } \\
\text { removal } \\
(\%)\end{array}$ \\
\hline 1 & -1.41 & 0 & 10.9 & 5 & 38.9 \\
2 & 0 & 0 & 25 & 5 & 48.9 \\
3 & 0 & -1.41 & 25 & 1.5 & 39.9 \\
4 & 1.41 & 0 & 39.1 & 5 & 53.7 \\
5 & 0 & 0 & 25 & 5 & 47.9 \\
6 & 0 & 0 & 25 & 5 & 50.0 \\
7 & 0 & 1.41 & 25 & 8.5 & 57.4 \\
8 & 0 & 0 & 25 & 5 & 54.2 \\
9 & 0 & 0 & 25 & 5 & 54.1 \\
10 & -1 & -1 & 15 & 2.5 & 40.9 \\
11 & -1 & 1 & 15 & 7.5 & 47.4 \\
12 & 0 & 0 & 25 & 5 & 52.8 \\
13 & 1 & 1 & 35 & 7.5 & 59.6 \\
14 & 1 & -1 & 35 & 2.5 & 49.5 \\
15 & 0 & 0 & 25 & 5 & 52.1 \\
16 & 0 & 0 & 25 & 5 & 48.9 \\
\hline
\end{tabular}

a Diethanolamine

$b$ Formaldehyde

experiments is mandatory to obtain a probable optimum response. It offers a better alternative to study the effect of variables and their response with minimum number of experiments (Montgomery 2001). This methodology was widely used in chemical processes (Beltrán-Heredia et al. 2009b) and offers a powerful tool for evaluating the intrinsic relationships between variables properly.

As we have reported in previous works (Beltrán-Heredia et al. 2009b), the collected data must be analyzed in a statistical manner using regression. Accordingly, the test factors must be coded as shown in Eq. (1):

$\chi_{i}=\frac{X_{i}-X_{i}^{x}}{\Delta X_{i}}$,

where $\chi_{i}$ is the coded value of the $i$ th independent variable, $X_{i}$ the natural value of the $i$ th independent variable, $X_{i}^{x}$ the natural value of the $i$ th independent variable at the center point, and $\Delta X_{i}$ is the value of the step change.

Since we have a large number of experimental variables, we have selected a factorial central composite design which included 8 replicates of the central value. It involves the use of a two-level factorial design with $2^{k}$ points combined with $2 k$ axial points and $n$ center runs, $k$ being the number of factors. $n$ is considered to be 8 and the two variables were the corresponding amounts of reagents. The working range for each one is presented in Table 1 . The whole list of experiments included 16 trials with different combinations of each factor. 
Fig. 5 Radom disposition of residuals in design of experiments

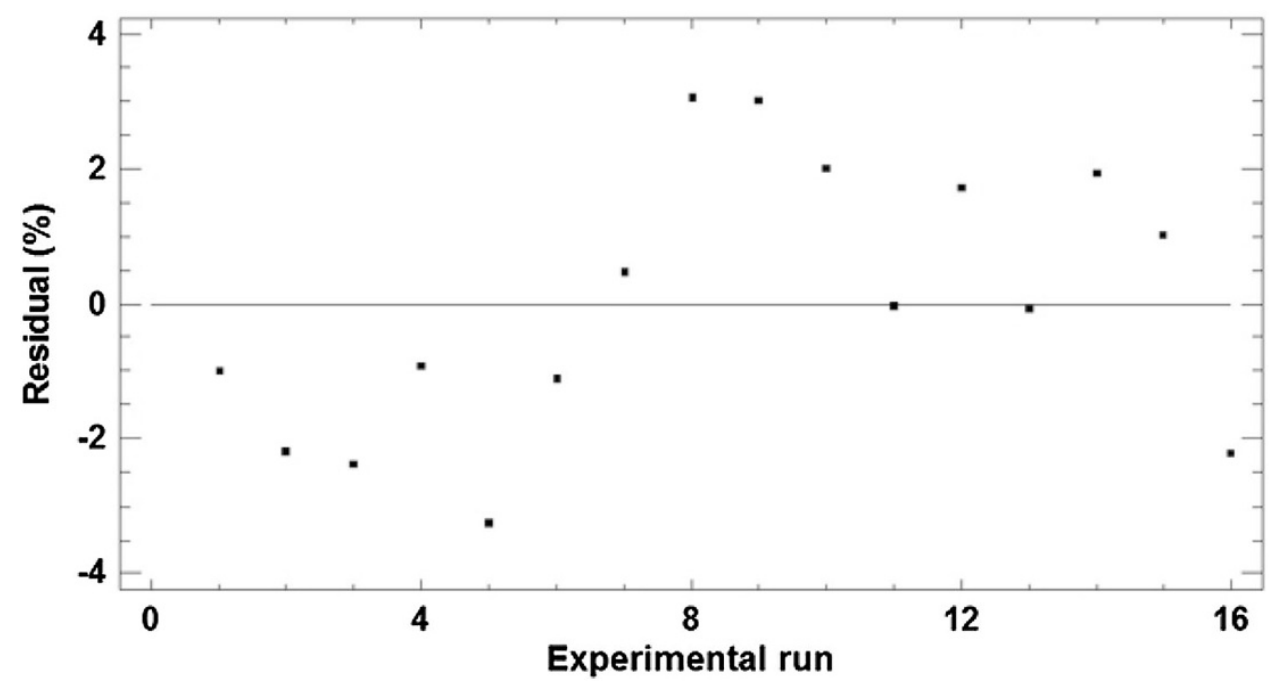

For evaluating the concomitant influence of the two variables, each coagulant inside the list of 16 combinations was tested on Alizarin violet $3 \mathrm{R}$ removal, according to the standard conditions of $\mathrm{pH} 7,20^{\circ} \mathrm{C}, 0.1 \mathrm{~L}$ of sample volume with an initial concentration of $100 \mathrm{mg} \mathrm{L}^{-1}$ of pollutant and $1.5 \mathrm{~mL}$ of coagulant. These experimental conditions were assumed according to previous screening experiments (data not shown) which showed the suitability of this working range. The performance trials were replicated three times and the average value of dye removal was retained as the consistent data for the DOE.

The evaluation of the optimization stage was made on the basis of removal efficiency (percentage removal of dye). Up to 5 effects (including the pure variables and the interaction between them) are considered in this model. The significativity level was set up at 0.05 and this is the criteria for assigning the significant ones, which were three of them. The adjusted correlation factor $r^{2}$ was above $85 \%$. Non-linear polynomic regression is carried out by taking into account the general Eq. (2) for data adjustment:

$Y=b_{0}+\sum_{j=1}^{k} b_{j} \chi_{j}+\sum_{i \neq j=1}^{k} b_{i j} \chi_{i} \chi_{j}+\sum_{j=1}^{k} b_{j j} \chi_{j}^{2}$

where $Y$ is the predicted response, $b_{0}$ the offset term, $b_{j}$ the linear effect, $b_{i j}$ the first-order interaction effect, $b_{j j}$ the squared effect, and $k$ is the number of independent variables.

In addition, there are no autocorrelation evidences since Fig. 5 does not show any pattern. This is a requirement in the design of experiments; moreover, conclusions raised from the experimental work would not be reliable if any kind of replicability pattern would have been found out. This figure shows the randomization of the errors, alternatively placed on both sides of 0 level. The randomization of the design was effective and an adequate adjustment in experimental data is observed therefore.

A graphical expression of this ANOVA test may be the Pareto graphic (Fig. 6). Bars represent the standarized effects of each involved factor, considering them as the initial effect and the interactions between them. Nonfilled bars are a graphical representation of positive-affecting factors, such as the dose of reagents. This means that this factor appears in the expression 2 behind a positive sign. On the other hand, filled bars represent negative-affecting factors. The vertical rule stands near to 2 and has to do with the signification level of ANOVA test, which is equal to $88 \%$ of confidence. Bars trespassing the vertical rule are inside the signification region, while bars behind it are not statistically significative. As can be seen, there are 3 significative factors, this means the experimental design explains adequately the synthesis and the influences of each parameter can be correlated to the effectiveness in removing Alizarin violet 3R.

Pareto graphic slightly offers an idea of the interaction between variables, which is shown in the bar AB in Fig. 6 . This bar does not reach the significativity limit, presented by the vertical rule. Specifically, Fig. 7 shows this aspect. As can be observed, the lines are not crossed, which means there is no interaction between variables. Moreover, both of them present a similar influence in the final response, as Fig. 8 depicts (main effects, graphic).

The most important graphical representation in the RSM is the surface graphic (Fig. 9). It plots Eq. 2 and allows to evaluate from a qualitative point of view how the behavior of the whole studied system is. As can be appreciated, the response is a quite convex surface inside the studied region, where the working variables rule in a very similar way. As DEA increases, the response variable tends to grow up. Similar behavior is presented by the other variable 
Fig. 6 Pareto graphic. Coded values

Fig. 7 Interaction of variables. Coded values

Fig. 8 Main effects. Coded values
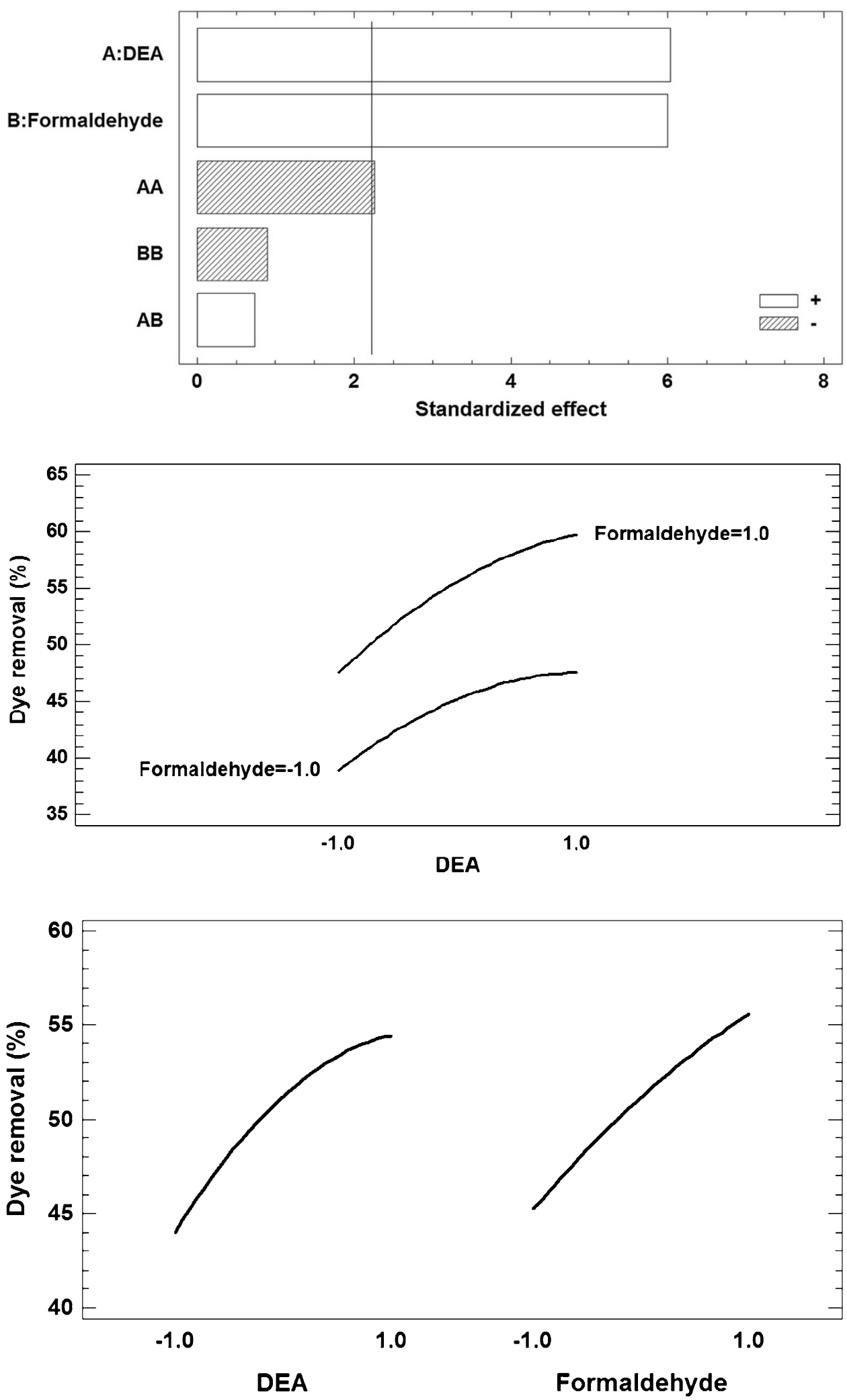

formaldehyde, and almost in the same level. Since there is no interaction between both variables, the first one does not affect the second one, and the optimum combination for these reagents seems to be in the positive extreme of the working range, that is, 1.41 and 1.41 for DEA and formaldehyde dose (39.1 and $8.5 \mathrm{~mL}$ respectively). This point 
Fig. 9 Response surface in design of experiments. Coded values

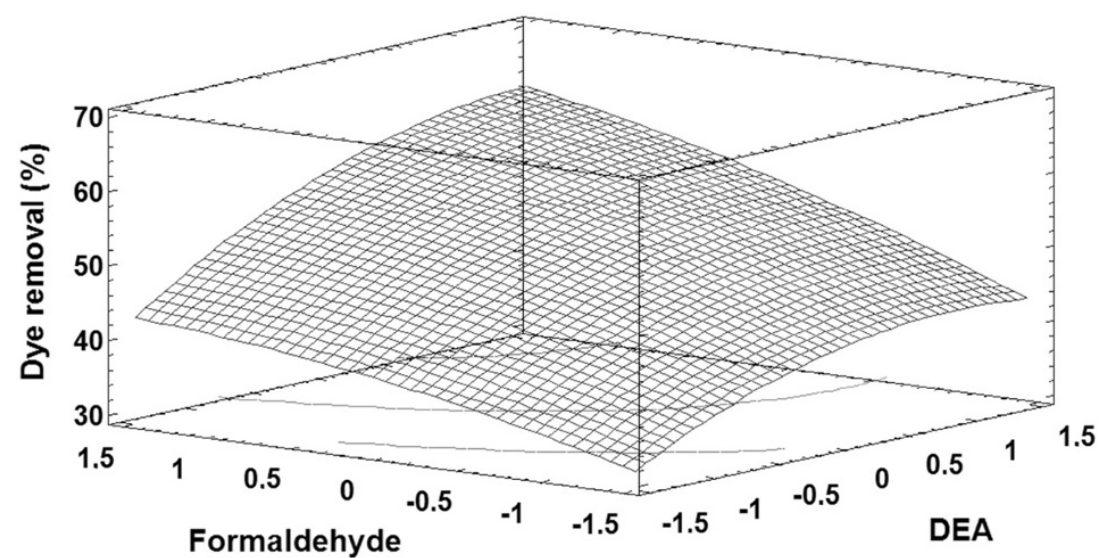

corresponds to the maximum dye removal, which is equal to $62 \%$. This is experimentally confirmed.

Preliminary performance of the optimum coagulant with dyes and surfactants

Once the optimum coagulant is identified, the feasibility of such product must be checked out with different polluted wastewater samples. This is the scope of two different screenings on dye and surfactant solutions. Although other target variables would give different results for the optimum combination of reagents, this was selected based on the DOE settings and on the fact that these are some of the most ubiquitous pollutants in water.

Final water quality is evaluated basing uniquely on the specific pollutant removal. This was decided according to the fact that we are dealing just with simulated wastewater samples. Further studies should include the use on real industrial wastewater. Previous papers (Sánchez-Maŕtin et al. 2009, 2010b) included some specific considerations on treated water quality and the experimental data indicated no quality decrease in other parameters, such as $\mathrm{BOD}_{5}$, COD, oxidizability or polyphenol content.

\section{Dyes}

The first screening is carried out on 9 dyes, with completely different chemical structures. As can be observed from Fig. 10, there exists a wide variety of efficiency levels within the group. All of them were treated in the same conditions: 1.5 $\mathrm{mL}$ of the optimum coagulant and $100 \mathrm{mg} \cdot \mathrm{L}^{-1}$ in a $100-\mathrm{mL}$ total volume. Anthraquinonic dyes, such as Alizarin violet $3 \mathrm{R}$ or Remazol brilliant blue, reached significantly high removal efficiency levels, up to $60 \%$, whereas the coagulation reached by other chemical groups is not so clear. As a matter of fact, azoic dyes such as Chicago Sky Blue, Palatine Fast Black, Amaranth or Tartrazine presented not a clear tendency: the first two ones were removed up to $90 \%$ but the rest presented a removal response almost null. This high specificity makes the coagulant a selective treatment agent, and the reasons for this may be found in the chemical structure of the dyes or even in their molecular weight. Amaranth and Tartrazine presented molecular mass of 500-600 g per mol, whereas Chicago sky blue 6B or Palatine Fast Black WAN presented 1,000-1,500 g per mol. For the rest of chemical groups (triphenylmethane, indigoid or quinoid) the coagulation efficiency is not very high.

\section{Surfactants}

On the other hand, Fig. 11 shows the removal efficiency of this optimum coagulant on 8 different surfactants. As can be observed, this percentage presents a wide range of variability, although the entire experimental series were made in the same conditions: $1.5 \mathrm{~mL}$ of coagulant and $50 \mathrm{mg} \mathrm{L}^{-1}$ of surfactant, $100 \mathrm{~mL}$ of total volume. There exists a probable behavior pattern when the removal efficiency is compared with the chemical structures showed in Fig. 4: low coagulant efficiency is linked to linear structures (without oxygen functional groups, such as ether or carboxylate). Aromatic rings, such as SDBS or SDDED, confer the surfactant a high affinity to the coagulant, as well as those with ether groups. These can be removed within 50-70\%. An intermediate situation is presented by linear detergents with carboxyl groups in the long chain, that is the case of SLSA or SDODS, which showed an average removal efficiency between 25 and $40 \%$. The natural origin of the coagulant and the wide variety in the coagulation efficiency (from less than $10 \%$ up to almost $70 \%$ ) are evidence of the interaction of many variables, not only the electrical affinities.

\section{Conclusions}

Tannin-based coagulants can be a source for new water and wastewater treatment. Specifically, tannins from

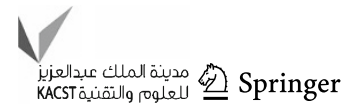


Fig. 10 Preliminar screening for dye removal

Fig. 11 Preliminary screening for surfactant removal
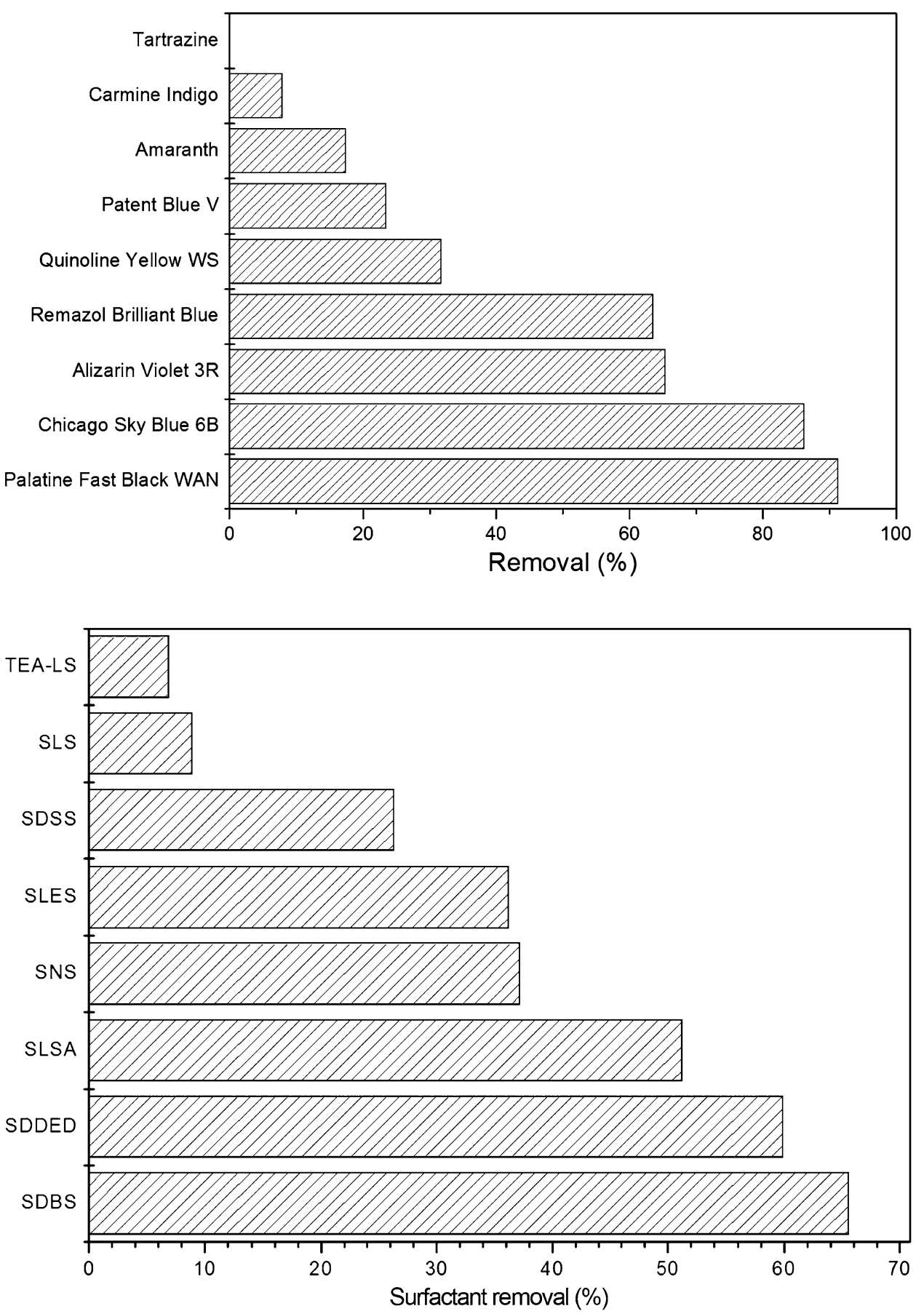

Quebracho colorado bark (that is, Schinopsis balansae) presented a promising feasibility as raw material for the synthesis of such coagulants, by means of diethanolamine and formaldehyde. The polymerization process can be optimized according to different amounts of reagents, giving the best combination at the maximum amounts of reagents. The optimum coagulant agent was tested on 9 dyes and 8 surfactants. The results were very interesting and the coagulant gave a high efficiency rate either in colorants or detergents. Further studies must be developed to generalize these results in a pilot plant or with other contaminants. Moreover, the experimental work with other kinds of tannin extracts or even including the chemical extraction itself in the water and wastewater treatment could be developed with the scope of minimizing costs and maximizing the water treatment possibility.

Acknowledgments This investigation has been supported by the COMISIÓN INTERMINISTERIAL DE CIENCIA Y TECNOLOGÍA (CICYT) CTQ 2010-14823/PPQ project. Dr. Sánchez-Martń would 
also thank the Regional Government of Extremadura and the researching group DEPROFE (University of Extremadura).

Open Access This article is distributed under the terms of the Creative Commons Attribution License which permits any use, distribution, and reproduction in any medium, provided the original author(s) and the source are credited.

\section{References}

Andriamirado L (2007) Water treatment handbook, vol 2. Degrèmont, Rueil-Malmaison

Beltrán-Heredia J, Sánchez-Martín J, Frutos-Blanco G (2009a) Schinopsis balansae tannin-based flocculant in removing sodium dodecyl benzene sulfonate. Sep Purif Technol 67(3):292-303

Beltrán-Heredia J, Sánchez-Martín J, Solera-Hernández C (2009b) Removal of sodium dodecyl benzene sulfonate from water by means of a new tannin-based coagulant: optimisation studies through design of experiments. Chem Eng J 153(1-3):56-61

Beltrán-Heredia J, Sánchez-Martín J, Gómez-Muñoz MC (2010) New coagulant agents from tannin extracts: Preliminary optimisation studies. Chem Eng J 162:1019-1025

Beltrán-Heredia J, Sánchez-Martín J, Barrado-Moreno M (2011a) Long-chain anionic surfactants in aqueous solution. Removal by Moringa oleifera coagulant. Chem Eng J 180:28-136

Beltrán-Heredia J, Sánchez-Martín J, Carmona-Murillo C (2011b) Adsorbents from Schinopsis balansae: Optimisation of significant variables. Ind Crops Prod 33(2): 409-417

Beltrán-Heredia J, Sánchez-Martín J, Dávila-Acedo MA (2011c) Optimization of the synthesis of a new coagulant from a tannin extract. J Hazard Mater 186(2-3):1704-1712

Beltrán-Heredia J, Sánchez-Martín J, Jiménez-Giles M (2011d) Tannin-based coagulants in the depuration of textile wastewater effluents: elimination of anthraquinonic dyes. Water Air Soil Pollut 222(1-4):53-64

Beltrán-Heredia J, Sánchez-Martín J, Martín-García L (2011e) Multiparameter quantitative optimization in the synthesis of a novel coagulant derived from tannin extracts for water treatment. Water Air Soil Pollut 223(4):2277-2286

Beltrán-Heredia J, Sánchez-Martín J, Rodríguez-Sánchez M (2011f) Textile wastewater purification through natural coagulants. Appl Water Sci 1(1):1-9

Bulatovic SM (2007) Dispersion, coagulation and flocculation. In: Handbook of flotation reagents. Elsevier, Amsterdam

Buzier R, Tusseau-Vuillemin M-H, Keirsbulck M, Mouchel J-M (2011) Inputs of total and labile trace metals from wastewater treatment plants effluents to the Seine River. Phys Chem Earth Parts A/B/C 36(12):500-505

Chinyama A, Chipato PT, Mangore E (2012) Sustainable sanitation systems for low income urban areas. A case of the city of Bulawayo, Zimbabwe. Phys Chem Earth Parts A/B/C 50-52: 233-238

Dorf RC (2001) Sustainable and appropriate technologies. Technology, humans, and society. Academic Press, San Diego

Flaten P (2001) Aluminium as a risk factor in Alzheimer's disease, with emphasis in drinking water. Brain Res Bull 55(2):187-196

Halling-Sorensen B, Nielsen SN, Lanzky PF, Ingerslev F, Holten Liitzhofl HC, Jorgensen SE (1998) Occurrence, fate and effects of pharmaceutical substances in the environment-a review. Chemosphere 36(2):357-393

Haslam E (1989) Plant polyphenols-vegetables and tannins revisited. Cambridge University Press, Cambridge

Matthews S, Mila I, Scalbert A, Nommelly DMX (1997) Extractable and non-extractable tannins in barks. Phytochemistry 45(2): 405-410

Miller SM, Fugate EJ, Craver VO, Smith JA, Zimmerman JB (2008) Towards understanding the efficacy and mechanism of Opuntia spp as a natural coagulant for potential application in water treatment. Environ Sci Technol 42(12):4274-4279

Montgomery DC (2001) Design and analysis of experiments, 5th edn. Wiley, New York

Muga HE, Mihelcic JR (2008) Sustainability of wastewater treatment technologies. J Environ Manag 88(3):437-447

Nakamoto Y, Tsunoda T, Ono K, Kaeyama N, Yazaki Y, Jiang F, Lawson F, Uhlherr PHT (2004) Method for the production of tannins and its use. US Patent 2004/0219234Al

Nazaroff WW, Álvarez-Cohen L (2001) Environmental engineering science. Wiley, New York

Pizzi A (2008) Tannins: major sources, properties and applications. In: Belgacem M, Galdini A (eds) Monomers, polymers and composites from renewable sources. Elsevier, Amsterdam

Sánchez-Martín J, González-Velasco M, Beltrán-Heredia J (2009) Acacia mearnsii de Wild tannin-based flocculant in water treatment. J Wood Chem Technol 29(2):119-135

Sánchez-Martín J, Beltrán-Heredia J, Dávila-Acedo MA, GómezMuñoz MC (2010a) Optimisation studies on tannin-based coagulants. In: Petridis GK (eds) Tannins: types, foods containing and nutrition. Nova Science Publishers, New York

Sánchez-Martín J, González-Velasco M, Beltrán-Heredia J (2010b) Surface water treatment with tannin-based coagulants from Quebracho (Schinopsis balansae). Chem Eng J 165:851-858

Schumacher EF (1987) Lo pequeño es hermoso (Small is beautiful). Hermann Blume, Madrid

Sharma SK, Sanghi R (eds) (2012) Advances in water treatment and pollution prevention. Springer, Dordrecht, Germany

Shaul MG, Holdsworth TJ, Dempsey RC, Dostal KA (1991) Fate of water soluble azo dyes in the activated sludge process. Chemosphere 22(1-2):107-119

Starkl M, Brunner N (2004) Feasibility versus sustainability in urban water management. J Environ Manag 71(3):245-260

StatPoint Technologies Inc. (2009) StatGraphics Centurion XVI User Manual. Virginia, USA

Tôei K, Fujii H (1977) Spectrophotometric determination of traces of anionic surfactants with methylene blue derivatives. Analytica Chimica Acta 90:319-322

Vivas N, Nonier MF, Vivas de Gaulejac N, Absalon C, Bertrand A, Mirabel M (2004) Differentiation of proanthocyanidin tannins from seeds, skins and stem of grapes (Vitis vinifera) and heartwood of quebracho (Schinopsis balansae) by matrixassisted laser desorption/ionization time-of-flight mass spectrometry and thiacidolysis/liquid chromatography/electrospray ionization mass spectrometry. Analytica Chimica Acta 513(1):247-256

WHO (2008) United Nation-global annual assesment of sanitation and drinking water. World Health Organization, Geneva

Ying CG (2006) Fate, behavior and effects of surfactants and their degradation products in the environment. Environ Int 32(3):417-431 